\title{
Physiological age of female bloodsucking midges (Diptera: Simuliidae) in the south of Tyumen region
}

\author{
O.A. Fiodorova ${ }^{1 *}$, S.A. Kozlov ${ }^{2}$ \\ ${ }^{1}$ All-Russian Scientific Research Institute of Veterinary Entomology and Arachnology - Branch of Federal \\ State Instution Federal Research Centre Tyumen Scientific Centre of Siberian Branch of the Russian \\ Academy of Sciences, Russia. \\ ${ }^{2}$ Tobolsk Complex Scientific Station of the Ural Branch of the Russian Academy of Sciences, \\ Tobolsk, Russia. \\ *Corresponding author E-mail: fiodorova-olia@mail.ru
}

\section{Received: 09.09.2020. Accepted: 21.10.2020}

\begin{abstract}
Despite the fact that blood-sucking flies (Diptera: Simuliidae) are mass bloodsuckers in a number of regions of Siberia and Far East, their biology in Russia and in countries of far abroad is still little studied. The purpose of this work is to study the physiological age of female flies in the subzone of the southern taiga of Tyumen region. Physiological age of female flies was determined by the method of V.P. Polovodova and T.S. Detinova, which was initially developed for mosquitoes, with a modification for black gnats by the number of "yellow bodies" - extensions of egg tube-ducks. Studies on the physiological age of females of one species of bloodsucking flies (Diptera: Simuliidae) Byssodon maculatus Mg., found in the subzone of the southern taiga of the forest zone. The species are mass bloodsuckers. It completes mainly one gonotrophic cycle, however by the end of the season the number females having laid eggs two times reaches $20-30 \%$. A large portion of the female population (10 - $22 \%$ ) fails to complete any gonotrophic cycle. Due to the cold times at the end of the summer season, there is a rejuvenation of the population due to the death of physiologically old females. Comparing changes in population and age composition of females allows to claim that the first two species have two and the last one - just one geniture during the season. Determination of the physiological age of the female or the number of gonotrophic cycles done by a female, and accordingly, number of blood suckings is of practical interest, not only a theoretical one, since it gives the possibility to evaluate the epidemiological situation in areas where flies are vectors of a number of infectious and invasionary diseases of thalaremia, onchocercosis, simulidotoxicosis. All this points to the relevance of the study of population density as vectors of infections in the territory of the Russian Federation. Unfortunately, it was not carried out extensively, and even some research is being done in the framework of narrow studies and only in some regions.
\end{abstract}

Keywords: Simuliidae; Gonotrophic cycle; Subzone of the Southern Taiga

\section{Introduction}

Blood-sucking flies (fem. Simuliidae) are small two-winged insects. They are one of the most important components of bloodsucking two-winged insects of the "gnat" complex, widely distributed in all landscape-geographical zones of Russia. Fauna and ecology of flies in the south of Tyumen region was studied by V.I. Bukshtynov (1962) and V.U. Mitrokhin (1964), V.D. Patrushev (1982). Nowadays, the remarkable climate warming and the anthropogenic impact on nature are increased. In this regard, the studying of fauna and ecology of blood-sucking flies becomes relevant. All families of lower blood-sucking bi-winged insects (Diptera, Orthorrpha), which are obligate hematophages, have a cyclical intermittent in the feeding of females sucking blood. Their life patterns are rather monotonous, they are free, periodically feeding blood suckers, characterized by the presence of a gonotrophic rhythm covering all the life periods of females (Beklimishev, 1940, 1942).

The study of biology of the most mass species of blood-sucking flies, which mainly determine high numbers in a particular area, is of great scientific and practical interest. Biology of flies in different geographical zones of Russia and CIS countries is poorly studied. There is definite lack of knowledge about the full cycle of species development from egg to imago. There is no complete data on physiological age of females, some works are dedicated to vectors (Magnarelli, Cupp, 1977; Gryaznov, 1995; Coupland, 1992; Davies, 1957, 1963; MeCall, 1997; Hoc, Wilkes, 1995; Anderson, 2012). The behaviour of bloodsuckers is largely determined by their need for additional blood nutrition needed for the development of sexual products. Populations - some species of bloodsucking flies - are characterized by the autogenous development of eggs. Many authors (Rubtsou, 1956; Vinogradova, 1965; Glukhova, 1968; Gryaznov, 1984a; Bodrova, 1984) believe that one of the most important causes of autogenesis is a full-fledged larval nutrition. However, the literature does not provide any concrete, actual evidence of dependence of the need of female flies in blood suction from the degree of development of their fat body due to the nature of larval nutrition (Savustyanenko, 1991)

In of our country, there is high activity of blood-sucking flies, of great medical - veterinary and epidemiological importance. For successful control over the population, it is necessary to know the patterns of its population formation first. Population size dynamics are known to be determined by the ratio between fertility and mortality at all stages of the life cycle (Beklemishev, 1957). Therefore, for proper organization of control of blood-sucking insects, a detailed study of the numerical indicators of fertility and its determinants are necessary. Data on fertility of flies in literature are limited to autopsy results of few females, numerical indicators are deprived of statistics (Shipitsyna, 1962; Petrova, 1963, Fiodorova,2018). The ecological conditionality of flies' fertility is poorly studied. The most comprehensive evidence of fertility is available only for the species Simuium damnosum Theo., a vector of 
onchocercosis in tropical countries (Mokry, 1980). However, flies are one of the most systematically complex groups due to the extraordinary external morphological similarity of different species (Rubtsou, 1962).

The literature also does not address issues of conditionality of flies' fertility on parasito-host relations. Only birds and mammals are known to be feeders of flies, with some authors indicating a certain food specialization to these two groups of feeders (Fallis, 1964; Balashov, 1982). The nature of trophic behaviour is one of the main prerequisites for the formation of a parasitic lifestyle of the bloodsucker (Tamarina, 1983). Figuring out the environmental factors and trophic connections that affect fertility will allow judging the breeding strategy of blood-sucking flies. Fight against blood sucking insects and disease vectors cannot be properly organized without a deep understanding of their dependence on various environmental factors, their reactions to the effects of these factors. The combination of physiological, morphological and ecological studies at the present stage forms the necessary basis for the development of measures to reduce the number of malicious species.

The purpose of our research is to study the physiological age of female blood-sucking flies (Dipterasimuliidae), in the subzone of the southern taiga of Tyumen region.

\section{Materials and Methods}

The experiment was carried out in the vicinity of Malye Velizhany of Nizhnetavda district of Tyumen region, located in the sub-zone of the southern taiga forest zone (Western Siberia, 1963; Tarasenkov, 1964; Atlas, 1971) in 2018.

The subzone of the southern taiga occupies the northern half of the agricultural area of the region. It is located between 60 and $57^{\circ} \mathrm{N}$, its width is $200-300 \mathrm{~km}$. Fir and birch-spruce grass forests are common in the area. The grass cover of the northern part of the subzone of the southern taiga is dominated by shallow grass, in the southern - by species peculiar to the broadleaf forests of the European part of the country. The subzone of the southern taiga belongs to the Kondo-Tawda Region. Extensive poorly drained, over-waterlogged plains are common in the southern taiga. There are very many lakes. Many high-moor peats and transition bogs, which occupy about $40 \%$ of the territory (Western Siberia, 1963). The climate is moderately continental. Average annual temperature $+0.2 \mathrm{C}$, average July $+17.5^{\circ} \mathrm{C}$, annual maximum $+37^{\circ} \mathrm{C}$. The average January temperature is minus $18^{\circ} \mathrm{C}$, the average minimum is minus $40^{\circ} \mathrm{C}$. Rainfall for the year amounts to $365 \mathrm{~mm}$, and most of it is noted in the warm period of the year -290 $\mathrm{mm}$. The duration of presence of the snow cover is 157 days, its average height is $38 \mathrm{~cm}$. The frost-free period lasts for $103-120$ days. The number of days with an average daily temperature of more than $+10^{\circ} \mathrm{C}$ is $102-107$, and more than $+15^{\circ} \mathrm{C}-$ an average of 60 days (Gvozdetsky, 1973).

The Nizhnetavdinskiy district is located on the interstream of Tura and Tavda rivers, which is a undulating flatlands, gradually decreasing in the north-eastern direction. The surface of the plain is oaken and waterlogged. The village of Nizhnjaya Tavda is located on the right bank of Tavda River. Cattle pastures, mostly forested, are waterlogged. Previously, grazing and camp keeping animals was practiced, and now the standing-pasture prevails.

Physiological age of female flies was determined by the number of extensions on egg tubes. This method was first developed by $\mathrm{V}$. P. Polovodova (1949) and T. S. Detinova (1949) for female mosquitoes. The method proved to be applicable to flies as well. The females were opened immediately after capture, and some - after a certain periods. Females, captured in nature, as well as bred from pupae, were kept in gauze orchards with sugar syrup and water. The autopsy of female flies was carried out according to the technique of E.N. Pavlovsky (1935), which represents a number of rules for the autopsy of small insects and mites. The tools used were a set of standard laboratory tools (dissecting needles, tweezers, scissors, etc.), as well as a "paddle-form" dissecting needle made according to the model of E.N. Pavlovsky (1935), having a wide end with a semicircular free end. Autopsies of females were conducted in saline on a clockwork glass under the MBS-1 microscope. Imagoes were caught with the help of entomological net with removable bags (Detinova et al., 1978). The imago flies were caught in the morning hours from 5 to 7 a.m. and in the evening hours from 7 to 8 p.m. The interval between accounts was 2 hours. The species of flies' imago was determined according to the determinative tables of Rubtsou (1956), Yankovsky (2002). In analysing the data, we adhered to the gonotrophic cycle scheme adopted in the literature (Refer Figures 1 and 2 according to Shypitsyna, 1962).

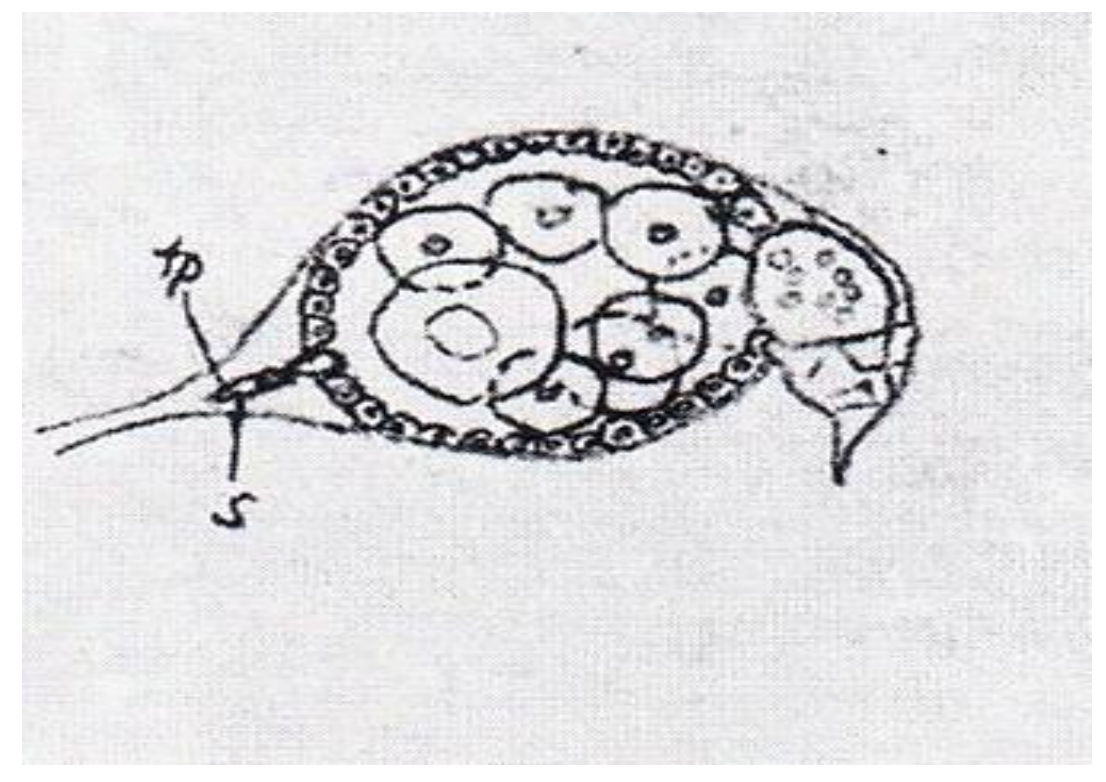

Figure 1. Egg tube of a nonclavified female (tp-tunic, s - "leg" -pedicel). 


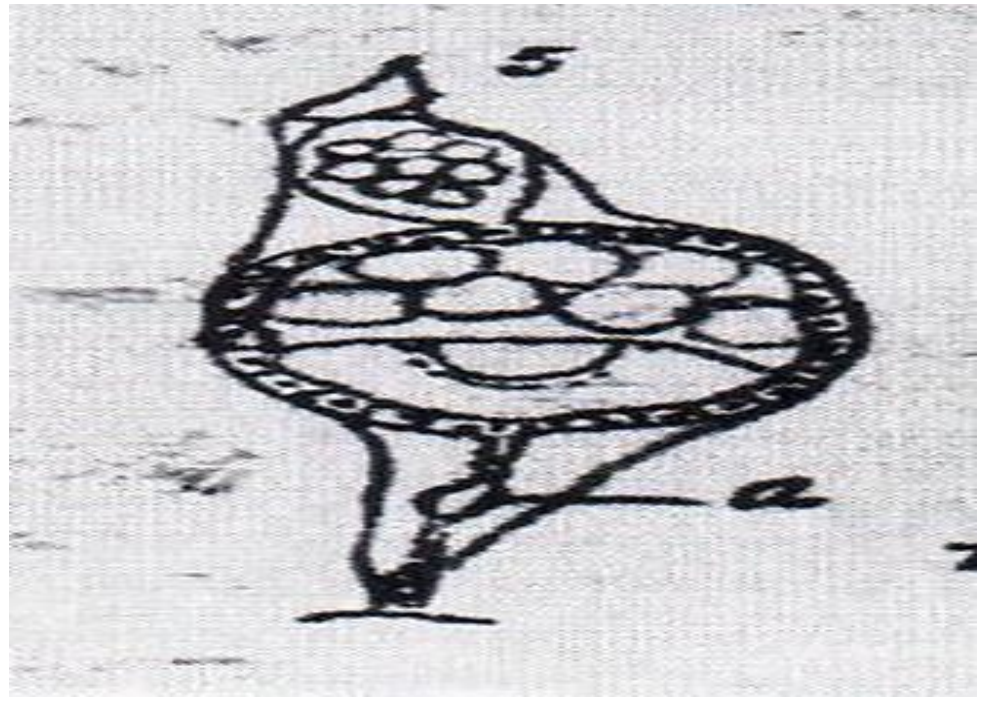

Figure 2. Egg tube of a female clavier (a - expansion of the end part of the egg tube).

\section{Results}

The species Byssodon maculatus (Meigen, 1804) is a mass species on the territory of Tyumen region, which was observed throughout the period of seasonal activity, and the majority of this species (82.1\%) was caught at the end of the first and second decade of June. The greatest species diversity is found in the third decade of July. Thus, the maximum number of blood-sucking flies is observed in June, the mass flight is due to the most numerous species.

The nature of the processes of gonotrophic cycle of females was studied in the conditions of the south, Tyumen region. Different landscape and climatic zones it has own features, the importance of which is necessary for practical purposes, as well as for studying the ecology of flies. The autopsies revealed that the vast majority of $B$. maculatus females do 1-2 gonotorophic cycles.

Based on the study of seasonal dynamics of the number of blood-sucking flies in the subzone of the southern taiga, as well as the analysis of the results of studies carried out earlier by other authors, it follows that the first individuals of flies can be found at the end of May. The highest numbers during the research season were observed in June and in the first decade of July. In abundance, the mass species is $B$. maculatus. The level of flies' number is determined by meteorological conditions prevailing in summer seasons. The flies stop flying mostly in August, but in some years their season can last until the end of September. The flies are active in the light of the day with increasing in evening (9 p.m.) and morning (7 a.m.) time. When illumination decreases during the day, the flies' numbers increase dramatically.

Simuliids are widely distributed on the territory of Russia and especially in Siberia. The main factors determining the high population of these insects are favourable climate conditions for their reproduction and existence combined with the abundance of brood biotopes (various water bodies and marsh formations) and imago habitats (presence of woody, shrubby or high herbaceous vegetation), as well as the presence of a sufficient number of warm-blooded animals - the source for blood nutrition of flies (Tables 1 and 2).

Table 1. Dates of flight of blood-sucking midges in southern taiga subzone (2018)

\begin{tabular}{|c|c|c|c|c|c|c|c|c|}
\hline \multirow[t]{3}{*}{ Types of midges } & \multicolumn{7}{|c|}{ The number of collected individuals by decades } & \multirow{3}{*}{$\begin{array}{c}\text { Occurrence } \\
\text { index, \% }\end{array}$} \\
\hline & \multicolumn{3}{|c|}{ June } & \multicolumn{2}{|c|}{ July } & & \multirow{2}{*}{$\begin{array}{c}\text { August } \\
1\end{array}$} & \\
\hline & 1 & 2 & 3 & 1 & 2 & 3 & & \\
\hline Byssodon maculatus & 1686 & 1556 & 369 & 145 & 65 & 81 & 47 & 100.0 \\
\hline Schoenbaueriapusilla & - & 1819 & 263 & 12 & - & 9 & - & 57.2 \\
\hline Odagmiaornata & - & - & - & - & - & 5 & - & 14.3 \\
\hline Sim. longipalpe & - & - & - & - & - & 2 & - & 14.3 \\
\hline Total individuals & 1686 & 3375 & 632 & 157 & 65 & 97 & 47 & - \\
\hline species & 1 & 2 & 2 & 2 & 1 & 4 & 1 & - \\
\hline
\end{tabular}

Table 2. The ratio of female midges age groups during 2018.

\section{Decades of months}

III Decade of June

I Decade of July

II Decade of July

III Decade of July

\section{Number of investigated females} 100

100 100 100

\section{Byssodon maculatus Mg.}

unclaimed

$100 / 100.0$

$88 / 88.0$

$74 / 74.0$

$57 / 57.0$

\section{1- unclaimed}

0

$12 / 12.0$

$26 / 26.0$

$41 / 41.0$

\section{2- unclaimed}

0

0

0

The numerator is the number of females; denominator is percentage of registered numbers. 
The first maximum of population was observed in the 1st decade of June, and the second was observed in the 1st and 2nd decade of July. A total of 800 females were studied. In the first collection, only those not layed the eggs are revealed among the females studied. One time layed eggs females were found in the third decade of June, amounting to $12 \%$. Not-eggs-layed females differed from eggs-layed in the lack of extensions. Flies laying one ovum, had extensions. In the second decade of July, the number of females who performed 1 gonotrophic cycle reached $50 \%$ of the number of attackers at this period. Whereas, not all blood suckers have the opportunity to get enough blood and lay eggs. A large proportion of the female population (10-22\%) fails to complete any gonotrophic cycles. By the end of the season, flies complete 1 gonotrophic cycle.

\section{Discussion}

In places with an abundant network of flowing water bodies, flies are one of the main components of the gnat. The scatterness of females, the soreness of their bites reduces human performance and productivity of farm animals. The territory of the Tyumen region is characterized by a large extensive river network, favourable for the development of flies, which are characterized by a wide ecological plasticity of the outcrop sites. The flies develop in fast-flowing reservoirs of varying size - from small streams to the largest rivers. Especially favourable for the clusters of flies are smaller waterfalls with bubbles of air and the presence of a suitable substrate, as well as rapid rolling, under bridges, below dams and impoundments, where the speed of the current exceeds $0.5 \mathrm{~m}$ per second.

Studies on fauna and ecology of blood-sucking flies in the south of the region were carried out mainly in the sixties - eighties of the last century, that is, they have not been studied for more than 40 years, and research on the physiological age of female bloodsucking flies in the subzone of the southern taiga has not been carried out for a long period of time and today this issue is of relevance as it represents the theoretical and practical interest in assessing the epidemiological situation in areas where flies are vectors of a number of infectious and invasive diseases. The seasonal course of flies' numbers is characterized by a single ramp-up in flies' numbers, due to a single geniture of the $B$. taculatus, species, while only one species dominates during of the entire summer season. The first rise in numbers takes place from the end of the first to the end of the third decade of June or the first decade of July. In other regions of Russia, researchers noted that the increase in the number of black gnats during the season is formed by not one, but several species. In the conditions of the Voronezh region, the duration of gonotorophic cycle of $B$. erytrocephala, is 2 genitures (Kolycheva, 1971). E.A. Marchukova (1966) showed that Sch. nigra in the areas of Voronezh makes up to three cycles, and the first cycle is autogenous.

Studies in the Krasnoyarsk region of Siberia have shown that some species of blood-sucking simulids are able to lay eggs more than one time. It was discovered that the number of gonotrophic cycles could be determined applying the same technique as the technique developed for mosquitoes, and that Simulium (Gnus) CholodkovsJtii Eubtsov completes up to five such cycles and $S$. galeratum Edw. - two or more (Detinova, Beltyukova, 1958). N.K. Shipitsyna (1962) indicated that in Krasnoyarsk Region river species of flies do more gonotrophic cycles than stream species. On the basis of this, the author believes that the fertility of the species developing in rivers is higher compared to the species being fused in streams. It is established that in Krasnoyarsk Region females of G. cholodkovskii do up to 5 egg raftings (Detinova, Beltyukova, 1958), Byssodon maculatus and Sch. pusilla - up to three egg raftings (Shipitsyna, 1962). Under Upper Kama conditions help Simulium morsitans to carry out up to three gonotrophic cycles, Simulium galeratum does up to four (Arkhipova, 1966).

\section{Conclusion}

Females of the most numerous species of flies in the conditions of the south of Tyumen region complete, mostly, one gonotrophic cycle. Comparison of changes in numbers and age composition of females allows to consider that B. maculatus has one geniture during the season.

\section{Acknodledgements}

The article was supported by he Ministry of Education and Science (Project "Monitoring the Epizootic Situation and Forecasts of the Development of Possible Outbreaks of Animal Parasitic Diseases" AAAA-A18-118020690240-3, "Biodiversity of wetland ecosystems in the south of Western Siberia", No. 0408-2019-0005).

\section{References}

Anderson, J.R., Shemanchuk, J.A. (1987). The Biology of Simulium arcticummallochin ALBERTA. Part II. Seasonal paritystructure and mermithid parasitism of populations attacking cattle and flying over the Atnabasca River, 119(1), 29-44.

Arkhipova, G.A., Beltyukova, K.N. (1970). On the population biology of river and long-palpated midges (family Simuliidae) - mass bloodsuckers of the Cis-Urals. Proceed. I Sc. Conf. of Zoologists of Pedagogical Institutes. Gorky.

Balashov, Yu.S. (1962). Parasite-host relations of arthropods with terrestrial vertebrates. L.eningrad. Nauka.

Beklemishev, V.N. (1957). Some general questions of the biology of blood-sucking lower dipterans. Honey, parasitology and a parasite diseases, 26(5), 562-566.

Bukshtynov, V.I. (1962). On the species composition and ecology of the gnus in the southwest of the Tyumen region. Problems Veterinary Sanitation. VNIIVS, 20, 122-133.

Davies, L. (1957). A Study of the Age of Females of Simulium ornatum Mg. (Diptera) attracted to Cattle. , The Canadian Entomologist, 48, 535-552.

Davies, L. (1963). Seasonal and Diurnal Changes in the Age-composition of Adult. Simulium venustum Say (Diptera) Populations near Ottawa. The Canadian Entomologist, 95(6), 654-667.

Detinova, T.S., Beltyakova, K.N. (1958). Contribution to the problem of repeated gonotrophic cycles in blackflies (family Simuliidae) from observations in the Krasnoyarsk region. Medical parasitology, 27(6), 686-688.

Detinova, T.S. (1949). The physiological changes in females ovaries of the An. Maculipennis Meig. Type. Medical parasitology, 18(4), 410413.

Detinova, T.S. (1962). Methods for determining the age composition of two-winged insects of medical significance. Geneva. World Health Organization.

Detinova, T.S., Rasnicin, S.P. (1978). Unification of methods of accounting of number of blood-sucking dipterous insects. Medical parasitology, 47(5), 84-92.

Fallis, A.M., Smith, S. M. (1964). Ether extracts from birds and CO£ as attractant for ornithophilic simuliids. Canad. J. Zool., 42(5), 723730. 
Fiodorova, O. A. (2018). Physiological age of female blood-sucking midges (Diptera, Ceratopogonidae) in the south of Tyumen oblast. Biosystems Diversity, 26(3), 179-182.

Gluhova, V. M. (1958). O gonotroficheskom cikle u mokrecov Culicoides (Diptera, Heleidae) v Karel'skoj. Parazitolocial papers Zoology Insititute AN USSR, 18, 239-254.

Gryaznov, A.I. (1984). Studying the Potential Fertility of Odagmia ornata Mg (Diptera, Simuliidae). In: Diptera insects (biology, ecology, morphology). Moscow State Universiy.

Gryaznov, A.I. (1995). Age-grading in blackflies (Diptera: Simuliidae) by ovariolar morphology, 85, 339-344.

Hoc, T.Q., Wilkes, T. J. (1995). Age determination in the blackfly Simulium woodi, a vector of onchocerciasis in Tanzania. Medical and Veterinary Entomology, 9(5), 16-24.

James B. (1992) Coupland Effect of Egg Mass Age on Subsequent Oviposition by Simulium reptans (Diptera: Simuliidae) Journal of Medical Entomology, 29(2), 293-295.

Kolycheva, R.V. (1971). On the biology of midge imago B. Erytrocephala DeGeer in the Khoper region of the Voronezh region. Voprosy Zoology and Physiology. Voronezh State University, 93, 29-33.

Magnarelli, L. A., Cupp, E. W. (1977). Physiological Age of Simulium Tuberosum and Simulium Venustum (Diptera: Simuliidae) in New York State, U.S.A. Journal of Medical Entomology, 13(4-5), 621-624.

Magnarelli, L. A., Cupp, E.W. (1977). Physiological Age of Simulium Tuberosum and Simulium Venustum (Diptera: Simuliidae) in New York State, U.S.A.

Marchukova, E.A. (1966). On the physiological age of the midges Schonbaueria matthiesseni End. in the vicinity of Voronezh. In Collection of zoological and parasitological works. Voronezh, Voronezh State University.

McCall, P. J., Wilson, M.D., Dueben, B.D., de Clare Bronsvoort, B.M., Heath, R.R. (1997). Similarity in oviposition aggregation pheromone composition within the Simulium damnosum (Diptera: Simuliidae) species complex, Bulletin of Entomological Research, 87(6), 609-616. Mitrokhin, V.U. (1964). Blood-sucking midges (family Simuliidae) of the Northern Trans-Urals. Thesis of Doctoral Dissertation. Leningrad.

Mokry, J.E. (1980). Laboratory studies on blood-feeding of blackflies (Diptera: Simuliidae). 2. Factors affecting fecundity.- Tropenmed. und Parasitol, 31(3), 374-380.

Patrusheva, V.D. (1982), Midges of Siberia and the Far East. Novosibirsk. Nauka.

Petrova, K.K. (1963). Gonotrophic cycle in midges. Thesis of Doctoral Dissertation. Chernigov.

Polovodova, V.G. (1949). Determination of the physiological age of the female Anopheles, that is, the number of gonotrophic cycles performed by her. Honey. parasitol. and parasitic diseases, 18 (4), 352-355.

Polovodova, V.P. (1949). Opredelenie fiziologicheskogo vozrasta samki Anopheles, to est' chislo prodelannyh gonotroficheskih ciklov. Medicinskaya parazitologiya, 7(4), 352-355.

Rubtsov, I.A. (1956). Methods for studying midges. Moscow. Leningrad.

Rubtsov, I.A. (1962). A brief guide to blood-sucking midges of the fauna of the USSR. Leningrd. Nauka.

Savustyanenko, T.L. (1991). Features of the gonotrophic cycle of midges (DIPTERA, SIMULIIDAE) depending on the nature of feeding of larvae. Thesis of Doctoral Dissertation. I.I. Shmalgauzen Institute of Zoology. Kiev.

Shipitsyna, N.K. (1962). On the gonotrophic cycle and age composition of the population of common species of blood-sucking midges (Diptera, family Simuliidae) in the vicinity of Krasnoyarsk. Communication 1. Gnuscholodcovskii, Simuliumreptansvar.galeratum. Medical parasitology and parasitic diseases, 31(1), 18-29.

Tamarina, N.A. (1983). Life scheme of the original form as the basis for the evolution of host-parasite relations. All-Union Congress of Parasitocenologists. Kiev.

Tarasenkov, G.N. (1964). Na otkrytyh prostranstvah rek Ob' i Irtysh (Priroda, byt i kul'tura Tyumenskoj oblasti).

Western Siberia. (1963). G. D. Richter (Ed.). Moscow: Publishing House of the Academy of Sciences of the USSR.

Yankovsky, A.V. (2002). Keys to mosquitoes (Diptera, Simuliidae) of Russia and adjacent territories (former USSR). Saint Petersburg, Russia.

\section{Citation:}

Fiodorova, O.A., Kozlov, S.A. (2020). Physiological age of female bloodsucking midges (Diptera: Simuliidae) in the South of Tyumen region. Ukrainian Journal of Ecology, 10(5), 105-109. 